\title{
Development of a Space Universal MOdular Architecture (SUMO)
}

\author{
Bernie F. Collins \\ Office of the Director of National Intelligence (ODNI) \\ Acquisition, Technology, and Facilities (AT\&F) \\ Washington, DC 20511 \\ 703-275-3525 \\ Bernie.F.Collins@dni.gov
}

\begin{abstract}
This concept paper proposes that the space community should develop and implement a universal standard for spacecraft modularity - to improve interoperability of spacecraft components. Pursuing a global industry consensus standard for open and modular spacecraft architecture will encourage trade, remove standards-related market barriers, and in the long run increase both value provided to customers and profitability of the space industrial sector. This concept paper sets out: (1) the goals for a SUMO standard and how it will benefit the space community; (2) background on spacecraft modularity and existing related standards; (3) the proposed technical scope of the current standardization effort; and (4) an approach for creating a SUMO standard.
\end{abstract}

\section{TABLE OF Contents}

1. INTRODUCTION 1

2. BACKGROUND 3

3. GOALS. 3

4. SPACECRAFT MOdULARITY

5. WHY ACT Now? 3

6. EARLY EFFORTS 10

7. NEW WORK 10 12

\section{INTRODUCTION}

This concept paper proposes that there is a global need to improve interoperability of spacecraft components and that a standard for modularity of spacecraft buses is the most effective way to achieve such interoperability. Pursuing a global standard for open and modular spacecraft architecture will therefore encourage trade and remove standards related market barriers. This should both strengthen the space industry by helping them compete in a growing international space market and enable the international market to leverage the capacity of the worldwide industrial base. It will also enable the industrial base to provide more functionality to its customers (government and commercial) at lower cost

${ }^{1}$ U.S Government work not protected by U.S. copyright 978-1-4673-18136/13/\$31.00 (C)2013 Crown because the international marketplace can create an economy of scale that the global customer base will be able to leverage. The resources expended to modify components for a range of specific applications will instead be available to improve sensors and payloads. This universal modular architecture will focus on spacecraft manufacturing stakeholders, including customers, manufacturing primes and tier 2 and 3 payload and component manufacturers. The interoperability focus is data interfaces (including software interoperability) and electrical interfaces; to the extent practical, this effort will avoid definition of mechanical interfaces. $^{2}$

The challenge at hand is that each spacecraft vendor has developed its own de facto proprietary standard for building avionics, and each vendor design represents a unique solution within the trade space of performance, size, weight, power, budget, and schedule that is optimized for a very specific purpose. Because each spacecraft vendor's architecture and de facto interface standards vary, lower tier manufacturers must integrate their components with custom interfaces and integration efforts, conforming to the highertier vendor's optimizations at the cost of more extensive non-recurring engineering (NRE). Standardized interfaces would reduce or eliminate the need for unique integration with each new component or application and thus lower the overall NRE costs for component reuse. Moreover, open and standardized architectures can more easily incorporate innovative and competitive products. Expecting spacecraft vendor and component manufacturers to protect their intellectual property (IP) through industry consensus standards may seem counter-intuitive. Yet - an increasing number of companies and their diverse user community are becoming less tolerant of "useless differentiation" through proprietary interfaces. $^{3}$ In fact, establishing interface compatibility can free up time and capital to differentiate products through innovation, rather than differentiating them based on their niche within an optimized design space.

\footnotetext{
${ }^{2}$ Mechanical interfaces may be addressed to some degree; for instance, certain form factors are associated with certain electrical interfaces and may be standardized.

${ }^{3} \mathrm{http}: / /$ www.worldstandardscooperation.org/newsletters/004/newsletter04.h tml
} 


\section{BACKGROUND}

As the global recession has forced many governments to reduce spending, standards which encourage design and construction of affordable satellites with interoperable components can spawn innovation in both component and overall spacecraft capabilities. Optimizing interoperable components in satellite architectures will eventually reduce a prime contractor's NRE expenses (for example, those associated with data interfaces and software functionality) when new components are introduced into heritage designs. This essentially removes a major barrier to market entry for smaller component suppliers. Concurrently, it enables prime contractors to offer shorter lead times and improved capabilities to the space customer base, both internationally and nationally. It is well documented that standards can produce significant and tangible benefits across: a range of industries; three core business functions (engineering, procurement and production); and key stakeholders - both demand side (customers) and supply side (vendors). ${ }^{4}$ With the help of an international standard written with industry needs in mind, it is expected that government and commercial interests will shift some of their buying power to more affordable and modular spacecraft designs over time - enabling them to invest their limited resources in more sophisticated sensors and payloads. While changing heritage systems to meet the standard will come with a cost, the transition can be eased by the use of adaptors and middleware so that adoption is incremental and targeted.

This concept paper sets out:

1. goals for a SUMO standard and how it will benefit the space community;

2. background on spacecraft modularity and existing related standards;

3. expected technical scope of the current standardization effort; and

4. approach for creating a SUMO standard.

\section{GoAls}

Our intention is to:

1. Develop a consensus US technical position concerning the desirability of developing a standardized modular architecture for space vehicle avionics that blends the best parts of current standards and any other approaches that may be proposed during the working group process.

2. Build that consensus by consulting and involving leading technical experts from the US satellite community, including the Department of Defense (DoD), NASA and commercial providers.

\footnotetext{
${ }^{4}$ World Standards Cooperation; No. 5, August 2012;

http://www.worldstandardscooperation.org/
}

3. Collaborate to develop the agreed-upon US technical position relative to the requirements for an internationally-standardized spacecraft avionics architecture. The group will initially focus on defining the problem and the desired characteristics of a preferred solution, rather than advancing any particular concrete implementation.

4. Advance the consensus US proposal to the Consultative Committee on Space Data Systems (CCSDS) and eventually, after reaching consensus within CCSDS Working Group, create the necessary international standard(s) that would then be advanced to ISO.

\section{SPaCeCRaft Modularity}

This project focuses on modularity because modular architecture supports both interoperability and design for change. Few, if any, major satellites are developed entirely from scratch; they reuse heritage technology, from individual components to entire vehicles. Current industry reuse largely occurs satellite by satellite, at best standardized across an individual prime contractor. Tier 2 and 3 satellite component manufacturers will, over time, develop specialized components for each prime with whom they interact. As a result, primes and their suppliers will be tightly coupled due to the prohibitive NRE costs for multiple vehicle/component interface designs. The goal in constructing a modular architecture is to decouple specialized component designs from vehicle systems engineering, so that:

- component technology advances can be amortized over a larger number of vehicles;

- primes will have more freedom to choose the best technology available; and

- decreased NRE costs will increase space sector profitability.

As an example, consider a spacecraft data bus: MIL-STD$1553 \mathrm{~B}$, which is used for the primary data bus in most U.S. military spacecraft, was published in September of 1978 . While terrestrial, personal, and mobile computing have seen enormous technological advances, the space industry's technology inertia has impeded technological advancement - even as more modern alternatives are being used in the similar domains of civil aviation and automotive design. This is likely to remain the case as long as components must be engineered to work with one bus specifically. The NRE associated with onboard satellite data interfaces includes more than just ensuring that data can flow across a cable; it includes ensuring that data sent across the satellite bus is sent in the format the bus requires; that it is sent using the right protocol, at the right time; that the timing allowances 
are compatible with the expectations of the data's receiver; that all of the data that must flow across the bus each computational period can be accommodated; that failure notifications and responses are consistent and maintain vehicle safety; and that all of these considerations have been analyzed and tested to ensure they work in the context of the system at hand. The retest effort alone needed to incorporate a new data bus would be prohibitive.

A modular architecture, on the other hand, could define a data bus at a conceptual level and specify a generic interface between any data bus and any component connected to the bus. Such an interface could contain specifics where appropriate, e.g., in the syntactic format of the data being sent from a component over the bus; and outline the form of the interface where variance is permitted but actual values must be known, e.g., the maximum uncertainty in data transmission times. Internal characteristics of the bus, e.g., whether usage is arbitrated by a controller or is allocated a periodic time slot a priori, would be excluded to enable flexibility in designs and adoption of new technologies. The test program for any particular data bus would be required to verify all stated characteristics of the interface, so that component-level test results could be reused and overall vehicle test times shortened significantly. This approach has been adopted with success in civil aviation, under the moniker Integrated Modular Avionics (IMA).

Defining a modular architecture to meet these goals involves four major steps:
1. Determining the scope of interoperability that is desired.

2. Designing the overall structure of the architecture.

3. Specifying the interfaces within the architecture of components that may change independently.

4. Choosing the appropriate level of standardization for vehicle subsystems.

We discuss each of these steps individually in the following sections.

\section{Determining the Scope of Desired Interoperability}

A standard to support interoperability through modularity must make effective tradeoffs between interface definition and design flexibility. Standardization comes at a cost: (1) cost to change existing components to meet the standard; (2) overhead cost associated with interfaces that are not tailormade for the vehicle at hand. Hence defining the right set of interfaces - and avoiding over-specification - is essential if the standard is to be adopted.

Table 1 organizes the characteristics of spacecraft buses that could potentially be standardized. For each aspect, it states whether, in this initial concept, that aspect is targeted for standardization, along with rationale for the choice. The Table will be coordinated throughout the space industry in order to achieve consensus.

TABLE 1. INTEROPERABILITY SCOPE

\begin{tabular}{|c|c|c|c|c|c|}
\hline \multicolumn{3}{|c|}{ Category } & Characteristic & $\begin{array}{c}\text { In } \\
\text { scope? }\end{array}$ & Rationale \\
\hline \multirow{14}{*}{ 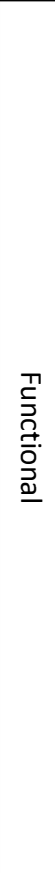 } & \multirow{9}{*}{ 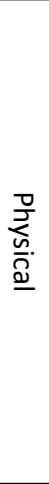 } & \multirow{3}{*}{ Data bus } & Connector & \multirow{3}{*}{ yes } & \multirow{3}{*}{$\begin{array}{l}\text { A commonized physical output will allow bus manufacturers to choose a } \\
\text { component based on price, performance, and availability rather than } \\
\text { because of the cost of the NRE to incorporate the component into the bus's } \\
\text { data network. Weight of potential middleware needed for adaptation is } \\
\text { low. }\end{array}$} \\
\hline & & & Cabling & & \\
\hline & & & Shielding & & \\
\hline & & \multirow{3}{*}{$\begin{array}{l}\text { Mechanical } \\
\text { interface }\end{array}$} & Bolt patterns & no & \multirow{3}{*}{$\begin{array}{l}\text { Too expensive/over-engineered: benefit is outweighed by the constraints } \\
\text { that would be imposed }\end{array}$} \\
\hline & & & Vibration isolation & no & \\
\hline & & & $\begin{array}{l}\text { Thermal isolation } \\
\text { and/or mgmt }\end{array}$ & no & \\
\hline & & \multirow{3}{*}{$\begin{array}{l}\text { Power } \\
\text { interface }\end{array}$} & Cable type & \multirow{3}{*}{ partial } & \multirow{3}{*}{$\begin{array}{l}\text { May specify standards for a few different voltage levels (e.g., } 28 \mathrm{~V}, 56 \mathrm{~V} \text {, } \\
112 \mathrm{~V} \text { ) to facilitate standardization with some differentiation to avoid } \\
\text { excessive inefficiency }\end{array}$} \\
\hline & & & Voltage & & \\
\hline & & & Shielding & & \\
\hline & \multirow{5}{*}{ 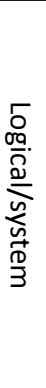 } & \multirow{5}{*}{ Data bus } & Data rate & no & $\begin{array}{l}\text { Requirement is that data bus can support rate needed by system. MIL-STD- } \\
\text { 1553B provides an implicit minimum. May increase as new technologies } \\
\text { become available; need to leave flexibility to take advantage of advances. }\end{array}$ \\
\hline & & & Jitter & yes & $\begin{array}{l}\text { May have different allowable categories but algorithms \& message } \\
\text { partitioning activity need to know tolerances }\end{array}$ \\
\hline & & & Latency & yes & $\begin{array}{l}\text { May have different allowable categories but algorithms \& message } \\
\text { partitioning activity need to know tolerances }\end{array}$ \\
\hline & & & Quality of service & yes & $\begin{array}{l}\text { May have different allowable categories but algorithms \& message } \\
\text { partitioning activity need to know tolerances }\end{array}$ \\
\hline & & & Protocol & no & Can specify interfaces that support multiple protocols \\
\hline
\end{tabular}




\begin{tabular}{|c|c|c|c|c|c|}
\hline \multicolumn{3}{|c|}{ Category } & Characteristic & $\begin{array}{c}\text { In } \\
\text { scope? }\end{array}$ & Rationale \\
\hline & & \multirow{3}{*}{$\begin{array}{l}\text { Component } \\
\text { (type-specific) }\end{array}$} & Bus interface & yes & Need components to be able to plug into whatever bus protocol is chosen \\
\hline & & & $\begin{array}{l}\text { Interface to } \\
\text { application software }\end{array}$ & varies & $\begin{array}{l}\text { Team will need to define what components may change, which drives which } \\
\text { interfaces need to be standardized }\end{array}$ \\
\hline & & & $\begin{array}{l}\text { Sensor } \\
\text { Precision/Accuracy }\end{array}$ & yes & $\begin{array}{l}\text { Specific precision/accuracy not defined, but characterization will be } \\
\text { required such that algorithms can statically determine whether a given } \\
\text { component in a class is within tolerance }\end{array}$ \\
\hline & & \multirow{3}{*}{$\begin{array}{l}\text { SW } \\
\text { infrastructure/ } \\
\text { services }\end{array}$} & $\begin{array}{l}\text { OS abstraction (incl. } \\
\text { CPU time \& space } \\
\text { partitioning) }\end{array}$ & yes & Need to allow components to work with different operating systems \\
\hline & & & $\begin{array}{l}\text { Network access } \\
\text { layer }\end{array}$ & yes & Need to allow components to work with different network types \\
\hline & & & Other services (TBD) & varies & $\begin{array}{l}\text { SOIS contains some candidates; these are points of coupling of the } \\
\text { applications and are needed if sets of subsystems are to be } \\
\text { reused/changed/rapidly assembled }\end{array}$ \\
\hline & & \multirow{2}{*}{$\begin{array}{l}\text { Intra-satellite } \\
\text { data }\end{array}$} & Command formats & no & Needed, but can be separated from the current effort \\
\hline & & & Telemetry formats & no & Needed, but can be separated from the current effort \\
\hline & & Applications & $\begin{array}{l}\text { GN\&C, C\&DH, EPS, } \\
\text { etc. }\end{array}$ & no & Would result in over-specification \\
\hline & & Payloads & General & partial & Payloads will conform to specification of a general component \\
\hline \multirow{17}{*}{ 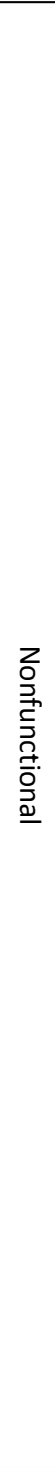 } & \multirow{8}{*}{ 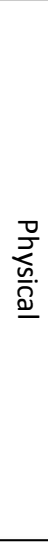 } & \multirow{2}{*}{ General } & $\begin{array}{l}\text { Parts, Materials and } \\
\text { Process } \\
\text { requirements }\end{array}$ & yes & $\begin{array}{l}\text { Have to standardize on space-qualified components and processes. Leads to } \\
\text { universal component certification. }\end{array}$ \\
\hline & & & $\begin{array}{l}\text { Component RMA } \\
\text { requirements }\end{array}$ & no & $\begin{array}{l}\text { Need system reliability to be within spec but component reliability can vary. } \\
\text { Minimum component reliabilities may be necessary in some cases, e.g., } \\
\text { switching hardware }\end{array}$ \\
\hline & & \multirow{5}{*}{$\begin{array}{l}\text { Environmental } \\
\text { test } \\
\text { requirements }\end{array}$} & Vibration & \multirow{5}{*}{ partial } & \multirow{5}{*}{$\begin{array}{l}\text { Need components certified across "regions" of launch and mission } \\
\text { environments to avoid unworkably narrow selection of components for any } \\
\text { particular system. May lead to unacceptable weight/power requirements } \\
\text { for some components; candidate initial component set to be standardized } \\
\text { across regions is torque rods, sun sensors, star trackers, GPS receivers, solar } \\
\text { cells, reaction wheels/CMGs, processor boards, and transponders. }\end{array}$} \\
\hline & & & Acoustic & & \\
\hline & & & Radiation & & \\
\hline & & & EMI/EMC & & \\
\hline & & & Thermal/vac & & \\
\hline & & Fault interface & $\begin{array}{l}\text { Allowable } \\
\text { unmasked faults }\end{array}$ & no & $\begin{array}{l}\text { Too difficult to define a priori at this time; push complexity into logical } \\
\text { interface, as is currently done }\end{array}$ \\
\hline & \multirow{9}{*}{ 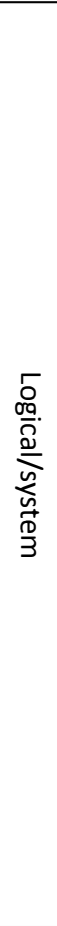 } & \multirow[t]{2}{*}{ General } & $\begin{array}{l}\text { SW \& system } \\
\text { dependability/RMA } \\
\text { requirements } \\
\text { Development } \\
\text { processes \& process } \\
\text { evidence }\end{array}$ & $\begin{array}{l}\text { one or } \\
\text { the } \\
\text { other }\end{array}$ & $\begin{array}{l}\text { Need a way to determine whether a piece of software has been developed } \\
\text { and tested to the appropriate level of assurance }\end{array}$ \\
\hline & & & Cyber Security & yes & $\begin{array}{l}\text { Vulnerabilities may exist, and may be public, in common elements; could } \\
\text { preclude adoption of standard if not addressed }\end{array}$ \\
\hline & & \multirow{4}{*}{ Fault interface } & $\begin{array}{l}\text { Component failure } \\
\text { notification format }\end{array}$ & yes & $\begin{array}{l}\text { Need to standardize so that fault handling is independent of } \\
\text { implementation }\end{array}$ \\
\hline & & & $\begin{array}{l}\text { Component failure } \\
\text { notification content }\end{array}$ & no & Push the complexity into higher layers to allow for flexibility \\
\hline & & & $\begin{array}{l}\text { Software failure } \\
\text { responses }\end{array}$ & no & Push the complexity into higher layers to allow for flexibility \\
\hline & & & $\begin{array}{l}\text { Format for database } \\
\text { of permissible value } \\
\text { ranges }\end{array}$ & yes & $\begin{array}{l}\text { Part of electronic data sheet for sensor; allows swapping of sensors without } \\
\text { retooling software interface }\end{array}$ \\
\hline & & \multirow{3}{*}{ Performance } & $\begin{array}{l}\text { Worst case } \\
\text { execution times }\end{array}$ & no & $\begin{array}{l}\text { Do not need to specify this for particular subsystems; can rely on static } \\
\text { analysis of integrated system and OS guarantees on time partitioning }\end{array}$ \\
\hline & & & $\begin{array}{l}\text { Algorithm precision } \\
\text { and accuracy }\end{array}$ & partial & $\begin{array}{l}\text { Requirements algorithms place on component precision/accuracy need to } \\
\text { be standardized, but precision/accuracy characterization of software } \\
\text { outputs varies too widely to be in scope at this time. }\end{array}$ \\
\hline & & & Quality of service & no & Not typically applicable to domain \\
\hline
\end{tabular}




\section{Designing the Architecture Structure}

Our conceptual architecture integrates both hardware connectivity and logical interfaces. As illustrated in Figure 1, the functionality within the architecture is defined in 4 major layers: individual components; component interconnection (data and electrical); software services that link the components with the flight software applications; and the flight software applications themselves. Component classes assigned to higher layers use the interfaces of lower layers to decouple their behavior from the specifics of other hardware and software components of the avionics.

\begin{tabular}{|c|c|c|c|}
\hline \multicolumn{3}{|l|}{ Software Applications } & \multirow{6}{*}{$\begin{array}{l}\text { Fault Interface } \\
\text { - Software and } \\
\text { system } \\
\text { depend- } \\
\text { ability and } \\
\text { process } \\
\text { require- } \\
\text { ments } \\
\text { - Component } \\
\text { failure } \\
\text { notification } \\
\text { format } \\
\text { - Database } \\
\text { format for } \\
\text { permissible } \\
\text { value ranges }\end{array}$} \\
\hline \multicolumn{3}{|c|}{$\begin{array}{l}\text { SW Infrastructure/services } \\
\text { - OS Abstraction (including time and space partitioning) } \\
\text { - Network Access Layer } \\
\text { - Other Services }\end{array}$} & \\
\hline \multicolumn{3}{|l|}{ Interconnect } & \\
\hline $\begin{array}{l}\text { Electrical Bus } \\
\text { - Voltage, Cable, Shielding }\end{array}$ & $\begin{array}{l}\text { Data Bus (Physical) } \\
\text { - Connector, Cable, } \\
\text { Shielding }\end{array}$ & $\begin{array}{l}\text { Data Bus Logical) } \\
\text { - Partitioning, } \\
\text { Jitter, Latency }\end{array}$ & \\
\hline \multicolumn{3}{|c|}{$\begin{array}{l}\text { Components } \\
\text { - Parts, Materials, \& Processes } \\
\text { - } \quad \text { Environmental Test Standards } \\
\text { - Interface to application software }\end{array}$} & \\
\hline Component & Component & Component & \\
\hline
\end{tabular}

FigURE 1. ARCHITECTURE LAYERS

Table 2 shows the scope (from Table 1) of each layer and references existing standards that the committee can use as a springboard for its activities.

TABLE 2. SCOPE AND REFERENCES FOR ARCHITECTURE LAYERS

\begin{tabular}{|l|l|l|l|l|}
\hline $\begin{array}{l}\text { Component/ } \\
\text { component } \\
\text { class }\end{array}$ & Scope & SPA reference & SAVOIR reference & $\begin{array}{l}\text { Other } \\
\text { References }\end{array}$ \\
\hline Hardware & $\begin{array}{l}\text { Data bus connector, cabling, } \\
\text { shielding } \\
\text { Electrical bus cable type, } \\
\text { voltage, shielding } \\
\text { Sensor precision, accuracy }\end{array}$ & $\begin{array}{l}\text { xTEDS } \\
\text { SPA Ontology Standard } \\
\text { SPA 28V Power Service Standard } \\
\text { SPA Physical Interface Standard } \\
\text { SPA Logical Interface Standard }\end{array}$ & $\begin{array}{l}\text { SOIS green book } \\
\text { sections 5, 2 }\end{array}$ & \\
\hline $\begin{array}{l}\text { Avionics } \\
\text { Infrastructure }\end{array}$ & $\begin{array}{l}\text { Data bus interface, jitter, } \\
\text { latency }\end{array}$ & $\begin{array}{l}\text { SPA SpaceWire standard } \\
\text { SPA System Timing Standard } \\
\text { SPA Networking Standard }\end{array}$ & $\begin{array}{l}\text { SOIS green book, } \\
\text { sections 4,2 }\end{array}$ & \\
\hline
\end{tabular}




\begin{tabular}{|l|l|l|l|l|}
\hline $\begin{array}{l}\text { Component/ } \\
\text { component } \\
\text { class }\end{array}$ & Scope & SPA reference & SAVOIR reference & $\begin{array}{l}\text { Other } \\
\text { References }\end{array}$ \\
\hline $\begin{array}{l}\text { Computing } \\
\text { Services }\end{array}$ & $\begin{array}{l}\text { Operating system abstraction } \\
\text { Network access layer } \\
\text { Other services, incl. data } \\
\text { handling, fault detection, } \\
\text { device interface } \\
\text { Component failure notification } \\
\text { format }\end{array}$ & & $\begin{array}{l}\text { SOIS green book, } \\
\text { sections 3,2,7 }\end{array}$ & \\
\hline $\begin{array}{l}\text { Applications } \\
\text { and Payloads }\end{array}$ & $\begin{array}{l}\text { Format for DB of permissible } \\
\text { value ranges } \\
\text { Algorithm precision and } \\
\text { accuracy } \\
\text { Flight software interface }\end{array}$ & & $\begin{array}{l}\text { PMP requirements } \\
\text { Vibration, acoustic, radiation, } \\
\text { EMI/EMC, thermal/vac test } \\
\text { requirements } \\
\text { SW \& system dependability \& } \\
\text { process requirements }\end{array}$ & SPA Test Bypass Extension \\
\hline $\begin{array}{l}\text { Test, } \\
\text { and Miability } \\
\text { Assurance }\end{array}$ & & $\begin{array}{l}\text { SOIS green book, } \\
\text { section 7 (minimal) }\end{array}$ & \\
\hline Cybersecurity & To be refined by experts & $\begin{array}{l}\text { CCSDS green books } \\
\text { "The Application of } \\
\text { CCSDS Protocols to } \\
\text { Secure Systems" and } \\
\text { "Security Threats } \\
\text { against Space } \\
\text { Missions" } \\
\text { SOIS green book, } \\
\text { section 6 }\end{array}$ & $\begin{array}{l}\text { MIL-STD- } \\
\text { environ- } \\
\text { mental } \\
\text { testing }\end{array}$ \\
\hline
\end{tabular}

\section{Specifying Architectural Interfaces}

Each architecture module (component, layer, service, software application, etc.) that falls within the committee scope (as defined in Table 1) will be worked individually by experts on the committee. The goal is to characterize each module well enough that its interactions with other modules can be defined and standardized as an interface.

Each pair of modules that interact directly within the architecture will be considered for interface standardization. The pieces to be defined during the interface specification process for a sample pair of modules (Module A and Module B) are illustrated in Figure 2. To create A's interface, the subject matter experts on module A would:

- Define common and variable features that A should be able to support

- State common requirements that A will place on its interfaces (i.e., requirements that other modules need to meet)

- Define the interfaces that A can provide to others (i.e., the requirements that $\mathrm{A}$ is able to meet)
- Meet with the subject matter experts on module B to iterate between what B can provide and what A needs, until the "right" interface (in terms of efficiency and flexibility) is reached.

The team working B would concurrently do the same, developing B's capabilities and needs so that the iteration step would produce a result for the pair. The same team could potentially work both $\mathrm{A}$ and $\mathrm{B}$, if the team had the necessary breadth of expertise.

With these clearly defined interfaces, modules can then be developed independent of each other, and may include the variability planned for them, without impacting one another. In other words, A's outputs and expected inputs should be independent of B's internal design, and vice versa. The specific definitions of the interfaces between modules in the SUMO architecture will constitute the SUMO standard. ${ }^{5}$

\footnotetext{
${ }^{5}$ It is acknowledged that full implementation of a CCSDS standard will require two successful prototype demonstrations.
} 


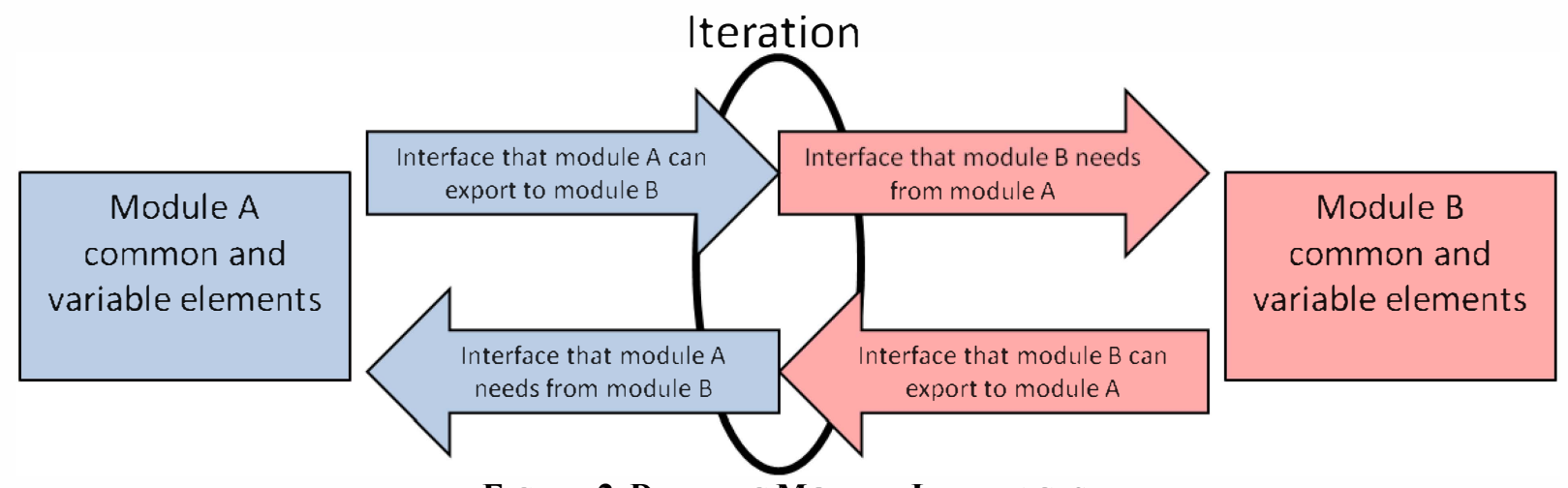

FigURE 2. DEFINING MODULE INTERFACES

\section{WhY ACT Now?}

A unified and internationally standardized open architecture for space vehicle components will support U.S. space component and payload manufacturers, as well as the global space community more generally, by removing market barriers and providing a "level playing field" on which internationally-interoperable products can be based. Moreover:

- There is a strong international desire to eliminate proprietary and regional standards that introduce market barriers which undermine trade.

- There is significant economic and strategic motivation among satellite component manufacturers to reduce NRE expenses. By establishing an internationally standardized modular architecture for space vehicles, satellite component manufacturers would reduce duplicative design and testing. As a result, certification procedures could allow for more time and capital to focus on design and performance improvements.

- A goal of the US National Space Policy - 2010 is to "promote a robust domestic commercial space industry" and "foster fair and open global trade and commerce through the promotion of suitable standards and regulations that have been developed with input from U.S. industry."

\section{EARLY EFFORTS}

\section{Air Force Research Laboratory (AFRL) Efforts - focus on extremely short satellite integration timelines.}

AFRL has developed a set of standards for a Space Plug and Play Architecture (SPA) in response to the need for extremely short design, fabrication, integration and test schedules. SPA's primary goal is to reduce satellite development phases from months and years to only a few days. SUMO targets the problem of reducing satellite development cost and schedule without requiring the very short timelines supported by SPA. SUMO's less strict development timeline requirements may result in a different architecture; SUMO's resulting standard set may not call out for self configuration and organization of components the key plug and play element within SPA. The CCSDS Spacecraft Onboard Interface Services (SOIS) working group has made substantial recent progress leveraging the AFRL SPA, scoping standard data interfaces, and designing specific Electronic Data Sheets (EDS) for a range of components. The EDSs will automate the inclusion of the components in the satellite data-bus and accelerate integration and, more importantly, enhance rapid reconfigurability of the bus. The SUMO team has refined the phases of the SUMO Implementation Plan to include the coordinated development \& adoption of EDSs for components -- based upon manufacturers' Interface Control Docs (ICDs) we can leverage AFRL's SPA \& CCSDS efforts for quick and early results.

More recently (2011), AFRL introduced Monarch (Modular Open Network Architecture) as a refinement of the earlier SPA concept. This version emphasizes a simplified implementation of the suite of SPA technologies, more optimized for large, high-assurance spacecraft with less emphasis on rapid development.

\section{European Space Agency (ESA) Efforts - Space Avionics Open Interface a $\underline{R}$ chitecture (SAVOIR) - an initiative to increase standardization and reuse within the space avionics community.}

SAVOIR is an initiative to federate the space avionics community, bringing customers, primes and suppliers together in order to improve the way that the European Space community builds avionics subsystems. The primary outputs of SAVOIR are:

- A reference avionics architecture for spacecraft platform hardware and software 
- A set of avionics external and internal interface specifications

- The definition of high-level architectural building blocks

- The detailed functional specification of selected architectural building blocks

- Implementations of selected building blocks at high TRL levels

- Process definition and assessment.

SUMO will be addressing a similar challenge to SAVOIR, and will build on the existing architectural effort, but may result in a more simplified architecture that addresses less of the detailed software functionality than SAVOIR currently does.

\section{Commercial Aerospace Efforts - Integrated Modular} Avionics (IMA) - a commercial avionics architecture that supports component modularity given shared computing resources.

IMA is an architectural trend in commercial avionics systems that reduces the design cost inherent in aviation's more traditional federated architectures. The basic principle of IMA is that several functions (even of different criticality levels) can share common computing resources ${ }^{6}$. In federated architectures, each function executes exclusively on its dedicated computer system, incurring duplicative space, weight, power and maintenance costs for the dedicated hardware. Co-locating multiple functions on the same set of resources, however, introduces concerns about the potential for fault propagation across functions. IMA supports cross-functional fault containment (mitigating the hazards arising from collocation) through time and space partitioning of the computing platform as described in the ARINC 653 Standard. Resource sharing introduces different roles and responsibilities for the software executing on the platform. RTCA DO-297, Integrated Modular Avionics Development Guidance and Certification Considerations, describes the roles and responsibilities for IMA programs based on best industry practice.

\section{NASA Efforts - Core Flight System (CFS) - a reusable software framework providing basic functionality but allowing for mission tailoring.}

The NASA Core Flight System (CFS) project has two major goals: (1) to reduce spacecraft development and integration times, similar to SPA, but in weeks rather than days; and (2) to reduce spacecraft development cost by allowing for reuse of much of the flight software functionality across multiple hardware architectures. To achieve hardware architecture and implementation independence, the CFS focuses on standardizing interfaces at several system layers. The CFS is the software

\footnotetext{
${ }^{6}$ Airlines Electronic Engineering Committee. ARINC specification 653: Avionics application software standard interface. Aeronautical Radio, Inc., January 1997.
}

framework in NASA's approach to spacecraft plug and play; it enables CFS components to be added and removed without rebuilding the software or even shutting down a running system.

\section{NASA Efforts - Common Avionics Architecture (Space AGE bus) - independent board-level functional building blocks that can be mixed and matched to define an avionics box.}

Defined to be the hardware analog to the software CFS, the SpaceAGE bus provides flexibility in defining avionics box functions. The architecture relies on a card frame mechanical approach to intra-box interfaces that eliminates the backplane and mechanical box chassis to reduce NRE. Boards are externally harnessed together via a common hardware building block called the HUB from which all cards are interconnected via a non-blocking crossbar switch capable of bridging between different NODE protocols. A serial communication physical layer is defined as well as the minimal set of generic signals necessary for space avionics intra-box interfaces. The Common Avionics Architecture is agonistic to protocols and box-to-box interfaces.

\section{Department of Energy (DOE) (Sandia National Laboratory) - Joint Architecture Standard (JAS) - a network-based payload architecture that is scalable, reliable, and reusable.}

Sandia and Los Alamos National Laboratories are currently developing a new architecture that will underlie future Nuclear Detonation Detection System (NDS) payload designs, regardless of host platform. JAS is a modular, node-based architecture that uses standard hardware designs, high-speed serial data interfaces, and reusable hardware and software IP. It uses a layered architectural design to isolate the software from hardware change impacts, and uses a service-based design to support flexible reuse of software to meet new payload needs. JAS offers COTS-based development and test environment for rapid system demonstration.

\section{NEW WORK}

Evaluate existing and emerging standards that address spacecraft component interoperability for data and electrical interfaces.

Develop a collaborative approach to gain a consensus US technical position that is likely to evolve into an international standard. It is important that the global marketplace be considered; hence we must eventually work with the larger international space community to forge international agreement on the best approach given the various standard-based architectures that are currently being developed. A first and vital step in securing such an 
international agreement is to craft a technical consensus position across the US space community.

\section{REFERENCES}

[1] American Institute of Aeronautics and Astronautics; "Space Plug-and-Play Architecture Standards Development Guidebook"; Draft August 2011.

[2] CCSDS - Consultative Committee on Space Data Systems (http://public.ccsds.org/about/default.aspx).

[3] CCSDS - "Spacecraft Onboard Interface Services" Draft Informational Report; CCSDS 850.0-G-2; Draft Green Book; April 2012.

[4] WSC - The World Standards Cooperation; (http://www.worldstandardscooperation.org/)

[5] Francis, N., Collier, P., and Lyke, J. "Optical Networking for Aerospace Systems Provisioned Through Plug and Play Avionics", Proceedings of the 2010 AIAA Infotech Conference, 20-22 Apr 2010 Atlanta, GA. (paper)

[6] Lanza, D., Vick, R. and Lyke, J., "The Space Plug- andPlay Avionics Common Data Dictionary - - Constructing the Language of SPA ", Proceedings of the 2010 AIAA Infotech Conference, 20-22 Apr 2010 Atlanta, GA.

[7] Lyke, James A.; “U.S. Air Force's Plug-and-Play Satellites”; IEEE Spectrum; August 2012.

[8] Taylor, Chris; "Spring CCSDS meetings Opening Plenary" (power point); ESA Estec; April 2012.

[9] Vera, Alonzo, Sibley, M, Ardalan, S., Avery, K., and Lyke, J. "Appliqué Sensor Interface Module Based on 90nm Rad- Hard Structured Application- Specific Integrated Circuit", Proceedings of the 2010 AIAA Infotech Conference, 20-22 Apr 2010 Atlanta, GA.

\section{AUTHOR BIOGRAPHY}

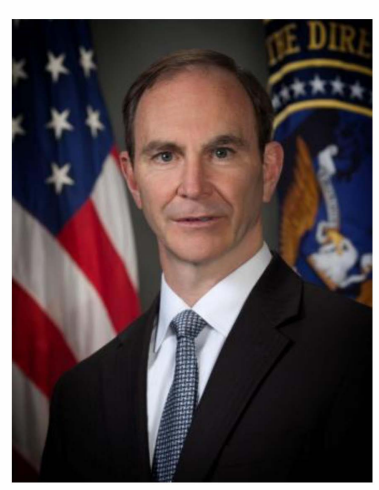

Bernie Collins currently serves as the Senior Advisor for the Director of Science and Technology in the Acquisition, Technology and Facilities Directorate for the Office of the Director of National Intelligence. In this capacity he leads activities to evaluate the space industrial base and to improve satellite acquisitions. He is developing and coordinating an innovative approach to acquiring satellites through industry consensus standards. Mr. Collins has extensive experience in the acquisition, development and operation of satellites. He was manager of two successful satellite programs and mission director for satellite operations. He also led overhead architecture studies and supported several independent program assessments and red teams. Mr. Collins is the recipient of the National Intelligence Medal of Achievement and the National Reconnaissance Office's Medal of Distinguished Performance. He received his Bachelors of Science in Electrical Engineering from the University of New Hampshire and his Masters of Science in Electrical Engineering, as a distinguished graduate, from the Air Force Institute of Technology. He is certified as a Program Manager Level 3. 